\title{
7 \\ A URGÊNCIA DO DEBATE DE GÊNERO, RAÇA E CLASSE NA FORMAÇÃO DE PROFISSIONAIS DE SAÚDE*
}

Jussara Francisca de Assis dos Santos

\section{Introdução}

0 desenvolvimento da reflexão trazida aqui tem como base a tese de doutorado intitulada "Enfrentamento à violência obstétrica contra mulheres negras numa maternidade pública municipal do Rio de Janeiro na perspectiva de gestoras (es) e profissionais de saúde" ${ }^{1}$. A metodologia da referida pesquisa teve por base a pesquisa qualitativa em estudo de caso onde foram coletados dados de 15 entrevistas semiestruturadas. Foram entrevistadas cinco gestoras e dez profissionais de saúde das áreas Serviço Social, Enfermagem e Medicina de uma maternidade localizada numa Área Programática (AP) cujo índice de morte materna no ano de 2016 foi o mais elevado do município do Rio de Janeiro.

Os resultados da referida pesquisa revelaram que o debate étnico racial não fez parte da formação das assistentes sociais entrevistadas, assim como das/os demais profissionais de saúde e gestoras, quer no nível da graduação ou da pós-graduação. Foi utilizado como parâmetro para tal análise o nível de conhecimento e contato das/os entrevistadas/os com a Política Nacional de Saúde Integral da População Negra (PNSIPN). Tal dado demonstra o quanto o investimento no debate étnico-racial faz sentido em todas as dimensões da vida e das políticas sociais, sobretudo, na área da saúde reprodutiva para que seja possível alcançar formas dignas de atendimento ao pré-natal, parto e pós-parto de mulheres populares, especialmente, negras e indígenas.

0 presente texto resulta da proposta de trabalho da autora cujo objetivo foi apresentar a projeção das atividades laborativas a serem desenvolvidas no período de estágio probatório, iniciado no dia 30 de setembro de 2019, no Departamento de Serviço Social de Niterói, para o cargo da carreira do magistério superior, classe Adjunto A, Nível 1, do quadro perma-

\footnotetext{
${ }^{*}$ DOI - 10.29388/978-65-86678-42-0-0-f.169-188

${ }^{1}$ Tese defendida através do Programa de Pós-Graduação em Serviço Social da Universidade Federal do Rio de Janeiro (PPGSS/UFRJ).
} 
nente da Universidade Federal Fluminense (UFF), Área: Fundamentos do Serviço Social. Com isso, a pretensão é problematizar a necessidade de incorporação da questão étnico-racial na formação de assistentes sociais a partir do tripé ensino, pesquisa e extensão. Tal proposta justifica-se pela necessidade de formar futuras (os) profissionais com competências e habilidades mínimas, tanto de intervir, quanto de gerir, propor e executar projetos, programas e políticas que façam frente às desigualdades sócio raciais tão presentes na realidade brasileira.

A Resolução 219/2005 que regulamenta a avaliação de desempenho docente no período de estágio probatório no âmbito da UFF determina que, após aprovação e nomeação no concurso público, - ao entrar em exercício, a (o) docente deve cumprir o seu estágio probatório em um período de 36 (trinta e seis) meses. A etapa inicial de avaliação do estágio probatório se dá com a apresentação de um plano de trabalho relativo aos 30 meses subsequentes ao período de nomeação para a docência.

Desta feita, as atividades propostas para os três anos de estágio probatório se nortearam pelo Projeto Pedagógico da Escola de Serviço Social - ESS/UFF, bem como pela direção social dada pelo Projeto Ético-Político do Serviço Social, que se materializa através do Código de Ética do profissional de Serviço Social (1993), da Lei de Regulamentação da Profissão (1993), Além dessas referências, há de se considerar as Diretrizes Curriculares (1996) e a Política Nacional de Estágio (2010), ambas pela Associação Brasileira de Ensino e Pesquisa em Serviço Social (ABEPSS).

Os princípios das Diretrizes Curriculares em Serviço Social buscam a formação de um perfil profissional que articule as dimensões teórico-metodológica, ético-política e técnico-operativa por compreender que a perspectiva fundante da formação profissional é um rigoroso trato teórico, histórico e metodológico da realidade social, com a adoção de uma teoria social crítica e de um método que permita a apreensão teórico-crítica do processo histórico como totalidade, considerando as particularidades da constituição e desenvolvimento do capitalismo e do Serviço Social na realidade brasileira.

As Diretrizes Curriculares procuram materializar o projeto de formação profissional que reconhece, a partir de um referencial crítico-dialético, a relação de unidade na diversidade entre teoria e prática. Segundo a ABEPSS (1996), o trabalho desenvolvido pelos profissionais de Serviço Social requisita algumas competências gerais que são fundamentais, como: I) apreensão crítica dos processos sociais de produção e reprodução das relações sociais numa perspectiva de totalidade; II) análise do movimento his- 
tórico da sociedade brasileira, apreendendo as particularidades do desenvolvimento do capitalismo no país e as particularidades regionais; III) compreensão do significado social da profissão e de seu desenvolvimento sócio-histórico, no cenário internacional e nacional, desvelando as possibilidades de ação contidas na realidade; IV) identificação das demandas presentes na sociedade, visando formular respostas profissionais para o enfrentamento das expressões da questão social.

Neste processo, é importante pontuar que no caso do Serviço Social brasileiro, as citadas Diretrizes Curriculares de 1996 (ABESS) determinou uma nova organização curricular baseada no tripé de conhecimentos formados pelos núcleos de fundamentação do trabalho da formação profissional, a saber: Núcleo de Fundamentos Teórico-Metodológicos da Vida Social, Núcleo de Fundamentos da Formação Sócio-histórica da Sociedade Brasileira e Núcleo de Fundamentos do Trabalho Profissional. Segundo a ABESS (1997) há a necessidade desses núcleos constituírem uma unidade indissociável que possibilita a apreensão da realidade social, tendo em vista o melhor preparo para a intervenção profissional. Logo,

[...] a formação profissional constitui-se de uma totalidade de conhecimentos que estão expressos nestes três núcleos, contextualizados historicamente e manifestos em suas particularidades (ABESS, 1997).

A formação profissional, conforme verificado através das Diretrizes Curriculares, não deve estar descolada da história que constituiu o Brasil e a sua população. Ao considerar tal articulação é de fundamental importância trazer para a formação profissional o debate étnico-racial dado o histórico escravocrata pelo qual essa sociedade se estruturou. Além disso, não se pode perder de vista a legitimidade das Diretrizes Curriculares Nacionais para a Educação das Relações Étnico-Raciais e para o Ensino de História e Cultura Afro-Brasileira e Africana, instituída pela Resolução no 01, de 17 de junho 2004, que determina sua efetivação em todos os níveis de formação.

É importante pontuar que, no Brasil, a relação entre escravidão, colonialismo/imperialismo/capitalismo e racismo oportuniza a compreensão da permanência e intensidade das assimetrias de raça/cor em nossa sociedade. Nos termos de Perpétuo (2000):

[...] a persistência histórica da raça como princípio classificatório não deve ser encarada como herança do passado, mas como um mecanis- 
mo social de reprodução da desigualdade racial, servindo aos interesses do grupo racialmente hegemônico (PERPÉTUO, 2000, p. 02).

Seguindo as colocações da autora, entende-se que as precárias condições pelas quais grande parte da população negra se encontra atualmente é decorrente das ínfimas oportunidades de transformação social e econômica causadas pela discriminação e preconceito racial (PERPÉTUO, 2000). 0 constructo em torno da cor/raça, com objetivos de subjugar, depreciar e desumanizar grupos não brancos tem no cenário da escravidão uma base importante. A partir desta reflexão, destaca-se a contribuição de Almeida (2018) ao pensar a escravidão a partir da economia política. 0 autor problematiza duas vertentes que tem provocado debates acerca do fenômeno da escravidão no Brasil e suas consequências para a população negra. A primeira delas seria de que o racismo recorre do legado da escravidão a partir do colonialismo. Almeida (2018) argumenta que:

[...] conforme este raciocínio, as sociedades contemporâneas, mesmo após o fim oficial dos regimes escravistas, permaneceriam presas a padrões mentais e institucionais escravocratas, ou seja, racistas, autoritários e violentos (ALMEIDA, 2018, p. 143).

A partir desta explicação pode-se entender que, como resquício da escravidão, o racismo assemelha-se a uma contaminação essencial que, principalmente em países periféricos, funcionaria como um impeditivo à modernização das economias e o surgimento de regimes democráticos (ALMEIDA, 2018).

A relação das mulheres negras brasileiras com o acesso à saúde reprodutiva não pode deixar de ser considerada no contexto mais amplo desta sociedade. Com o objetivo de identificar fatores associados à avaliação das mulheres quanto às relações profissionais de saúde/parturiente e como esses fatores influenciam a satisfação com o atendimento ao parto, a pesquisa intitulada "Desigualdades sociais e satisfação das mulheres com o atendimento ao parto no Brasil: estudo nacional de base hospitalar" (D'ORSI et al, 2014) revelou que a cor da pele das entrevistadas foi associada à pior avaliação do tempo de espera até ser atendida e menos privacidade nos exames. Quanto ao trabalho de parto, as pesquisadoras identificaram menores níveis de respeito e maior relato de violência dirigidos às mulheres pretas e pardas. 
A partir destas constatações, verificou-se a oportunidade de propor o aprofundamento do debate étnico-racial na formação a partir da Escola de Serviço Social da UFF, Niterói. As ações colocadas aqui não pretende ficar apenas no âmbito da ESS, mas, sobretudo, de dialogar com movimentos sociais populares, reforçando a articulação necessária no que diz respeito à luta coletiva em prol da saúde da população negra. Tal proposta relacionase às áreas de conhecimento da autora, ou seja, a Questão Racial na Sociedade Brasileira articulada aos Fundamentos do Trabalho Profissional em Serviço Social; em outras palavras, a articulação entre gênero, raça e classe tem sido proposta apresentada à categoria profissional, tendo em vista a urgência em formar profissionais capazes de intervir numa realidade social particularizada por tais dimensões como a realidade brasileira

\section{Gênero, raça e classe: articulação necessária para en- tender a violência obstétrica}

A realidade que envolve práticas identificadas como violência obstétrica articulada ao racismo demonstra a forma como a sociedade brasileira se conformou, ou seja, baseada no racismo estrutural, onde a dinâmica das instituições - especialmente, das instituições de saúde - revelam o quanto que o corpo negro ainda tende a ser relacionado à desumanização e coisificação. No que se refere à vida reprodutiva de mulheres negras, passado e presente guardam aproximações que precisam ser consideradas para melhor entendimento do que venha a ser violência obstétrica dirigida a este grupo social.

A institucionalização da medicina no Brasil teve ligação intensa entre a escravidão e o aprendizado médico. Lima (2011), ao pesquisar o corpo escravizado como objeto de práticas médicas no Rio de Janeiro, entre 1830 e 1850, constata que, nos leitos da Santa Casa de Misericórdia, "Os cativos tiveram grande importância para o treinamento e ensino da medicina ao disponibilizar involuntariamente seus corpos" (LIMA, 2011, p. 190).

Ao destacar a prática cirúrgica e o corpo feminino, analisa a gênese da obstetrícia no Brasil, onde as mulheres negras escravizadas e/ou libertas pobres eram utilizadas para o desenvolvimento de conhecimentos relativos ao parto. Os cursos de parto (voltados para a certificação de parteiras elitizadas) iniciados por volta de 1840 também utilizavam os corpos das escravizadas como laboratório. Mott (1999) relata que, ao mesmo tempo que os cursos excluíam as mulheres escravizadas, era, especialmente, sobre o 
corpo dessas mulheres (das parturientes escravas, negras livres e pobres) que as alunas do curso de parteiras e os alunos de medicina adquiriram a sua prática.

Vale destacar que, no âmbito internacional, por volta de 1850, o chamado pai da ginecologia moderna, James Marion Sims, médico americano, ficou conhecido por suas inovações na área. 0 mesmo foi responsável pela criação do espéculo, utilizado na cirurgia para reparação de fístula, assim como pela extração de pedras da vesícula e, sobretudo, pela iniciação de tratamentos de fertilidade (inseminação artificial). Tais descobertas, tidas como um importante avanço na área da medicina, se deram a partir da utilização de negras escravizadas do estado do Alabama. Embora a anestesia já tivesse sido descoberta nesta época, todas as cirurgias eram realizadas sem este recurso. Uma das referidas mulheres chegou a ser operada mais de 30 vezes sem inibição da dor (WISNIEWSKI, 2013).

No processo de formação das profissões, sobretudo, das profissões de saúde, se faz urgente a necessidade de considerar os sujeitos sociais de forma integral, apreendendo as múltiplas mediações do tecido social, isto é, através da cultura, trabalho, religião, economia, política, gênero, raça/etnia, geração, condição física etc. Expressões materiais e sociais que implicam na sociabilidade humana mediada pelo processo de produção e reprodução da vida social onde a particularidade brasileira está marcada pelas relações desiguais entre grupos raciais e de gênero diferenciados.

A recente história do Brasil revela que esta sociedade tem em sua trajetória formas conservadoras, patrimoniais e patriarcais de organização. Nos últimos anos, tais características têm tomado contornos mais radicais à medida que a crise estrutural do sistema capitalista exige respostas, inten samente, severas. Neste contexto, o chamado neoconservadorismo, representado pela "busca de legitimação da opressão dos trabalhadores ou pela criminalização dos movimentos sociais, da pobreza e da militarização da vida cotidiana" (BARROCO, 2011, p. 210), incide, de forma mais intensa, so bre àquelas (es) tidas (os) como, historicamente, destituídas (os) de justiça social, econômica e política. No caso do Brasil, àquelas (es) que compõem este contingente de destituídos são, em sua maioria, pertencentes à população negra (pretas (os) e pardas (os)) e a população indígena.

Para justificar a relevância do debate étnico-racial na formação profissional, podemos considerar a realidade que envolve as categorias trabalho e saúde ${ }^{2}$ e o quanto a população negra encontra-se na base da pirâ-

\footnotetext{
${ }^{2}$ Destacamos as categorias trabalho e saúde porque são as que têm feito parte das análises da autora ao longo da trajetória acadêmica. Contudo, entendemos que, também ao conside-
} 
mide social, vivenciando as maiores desvantagens no que diz respeito a tais direitos.

Dados da Pesquisa "Desigualdades Sociais por Cor ou Raça no Brasil”, realizada pelo Instituto Brasileiro de Geografia e Estatística (IBGE) e divulgado pelo Informativo Estudos e Pesquisas/Informação Demográfica e Socioeconômica n. 41, revelam que nas esferas essenciais à reprodução das condições de vida, as desigualdades sociais, quando desagregadas por cor/raça, demonstram sua face mais perversa. Ao analisar o mercado de trabalho constatou-se que, no ano de 2018, 57,7 milhões de pessoas pretas e pardas formavam a maior parte da força laboral no país, isto é, 25,2\% a mais que a população branca (46,1 milhões). Por outro lado, quando verificada a população desocupada e a população subutilizada, conclui-se que pessoas pretas e pardas estão mais representadas nestas esferas, já que, apesar de serem pouco mais da metade da força de trabalho (54,9\%), estas pessoas formam cerca de $2 / 3$ dos desocupados $(64,2 \%)$ e dos subutilizados $(66,1 \%)$ na força de trabalho em 2018 (IBGE, 2019, p. 02).

Quando considerados os níveis de instrução, verifica-se que a desvantagem se mantém. Os níveis de subutilização da força de trabalho são maiores entre pretas (os) e pardas (os) em qualquer grau de instrução, sendo, relativamente menor para aquelas (es) que possuem nível superior.

Tais dados demonstram o quanto a informalidade conforma o mercado de trabalho brasileiro. Em consequência aumenta-se o trabalho precário e/ou a falta de acesso à proteção social, limitando-se, assim, o acesso aos direitos básicos, tais como a remuneração pelo salário mínimo e à aposentadoria. Segundo dados coletados e informados pelo IBGE, no ano de 2018, “[...] enquanto $34,6 \%$ das pessoas ocupadas de cor ou raça branca estavam em ocupações informais, entre as de cor ou raça preta ou parda esse percentual atingiu 47,3\%" (IBGE, 2019, p. 02).

Quando considerados os dados desagregados por sexo é possível notar que as mulheres negras encontram-se ainda mais em desvantagem.

rar os demais direitos - tais como: educação, habitação, lazer, envelhecimento, mobilidade, direito à cidade, meio ambiente etc. - a população negra, sobretudo, as mulheres negras en contram-se em histórica desvantagem. 
Figura 01: Pessoas em ocupações informais (\%)

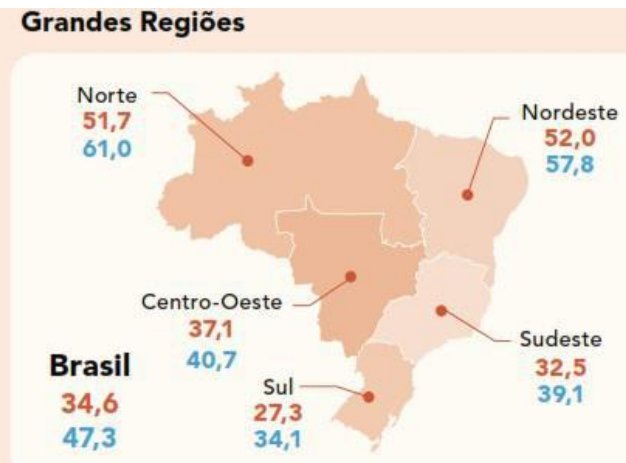

\section{Sexo}

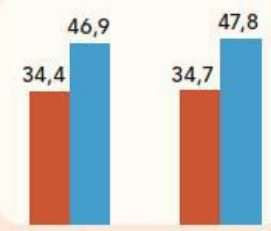

Homens Mulheres

32,5

Branca

Preta

ou parda

Fonte: IBGE, Pesquisa Nacional por Amostra de Domicílios Contínua 2018. Nota: Pessoas de 14 ou mais anos de idade.

Há que chamar atenção ao fato das mulheres pretas e pardas receberem menos da metade dos rendimentos auferidos aos homens brancos. Estes, historicamente, apresentam maiores rendimentos em comparação aos demais grupos populacionais (mulheres brancas, homens negros e mulheres negras). 0 grupo que apresenta maior distância dos homens brancos, no que tange rendimentos são as mulheres negras, ou seja, apresentam $44,4 \%$ de diferença.

Gráfico 01: Razão de rendimento das pessoas ocupadas (\%)

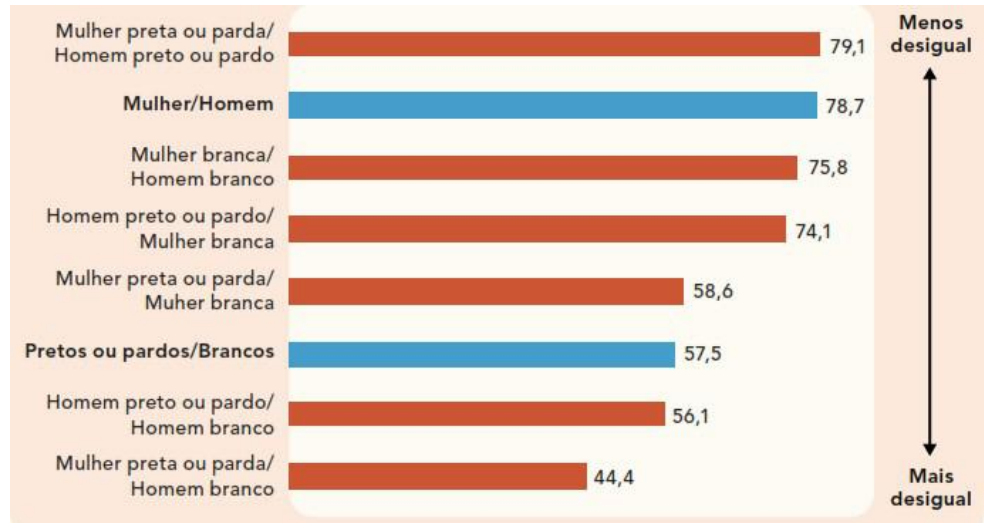

Fonte: IBGE, Pesquisa Nacional por Amostra de Domicílios Contínua 2018.

Nota: Pessoas de 14 ou mais anos de idade. 
No que diz respeito à saúde, é sabido que a população negra é majoritariamente dependente do Sistema Único de Saúde (SUS), pois cerca de $70 \%$ de suas (seus) usuárias (os) são negras (os). Logo, cabe ressaltar a necessidade da defesa do SUS público, que promova a universalidade da assistência de forma equânime. Embora as diretrizes do SUS afirme como princípios a universalidade, integralidade e igualdade, estudos demonstram o quanto as disparidades em saúde estão relacionadas às relações raciais. A partir do entendimento acerca do racismo estrutural, compreende-se que 0 racismo institucional que envolve o campo da saúde tem impactado o acesso e a qualidade da assistência nas unidades de saúde. Para Werneck (2016):

[...] o racismo institucional (RI), que possivelmente é a dimensão mais negligenciada do racismo, desloca-se da dimensão individual e instaura a dimensão estrutural, correspondendo a formas organizativas, políticas, práticas e normas que resultam em tratamentos e resultados desiguais. É também denominado racismo sistêmico e garante a exclusão seletiva dos grupos racialmente subordinados, atuando como alavanca importante da exclusão diferenciada de diferentes sujeitos nesses grupos (WERNECK, 2016, p. 541-542).

A última Pesquisa Nacional de Saúde (PNS), realizada em 2013 e também de responsabilidade do IBGE, demonstra dados importantes ao considerar o fator racial das informações. A mamografia, exame fundamental para diagnóstico do câncer de mama, teve menor incidência entre as mulheres pretas e pardas. Este tipo de câncer é um dos que mais causa mortes de mulheres no Brasil. De acordo com o Instituto Nacional do Câncer (INCA), a mamografia permite a detecção precoce da doença por mostrar lesões ainda na fase inicial. 
Gráfico 02: Proporção de mulheres que realizaram exame de mamografia nos últimos dois anos anteriores à pesquisa, na população de mulheres de 50 a 69 anos de idade, com indicação do intervalo de confiança de 95\%, segundo o nível de instrução e a cor ou raça - Brasil - 2013.

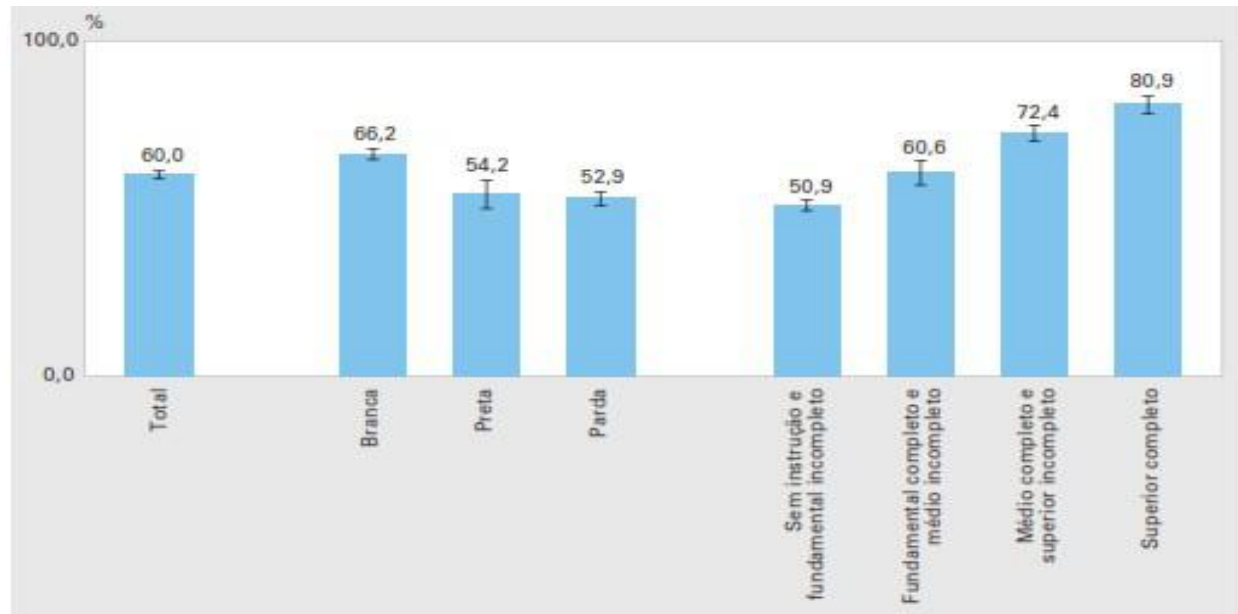

Fonte: IBGE, Diretoria de Pesquisas, Coordenação de Trabalho e Rendimento, Pesquisa Nacional de Saúde 2013.

A mesma pesquisa revela ainda que havia 146,3 milhões de pessoas de 18 anos ou mais de idade no Brasil. Deste total, 10,6\% (15,5 milhões) afirmaram que já se sentiram discriminadas ou tratadas de maneira pior que as outras pessoas no serviço de saúde, por médico ou outro profissional de saúde. Neste universo, destacaram-se: as mulheres (11,6\%); as pessoas de 30 a 39 anos $(11,9 \%)$ e de 40 a 59 anos de idade (12,0\%); as pessoas de cor preta $(11,9 \%)$ e parda $(11,4 \%)$; e as pessoas sem instrução ou com fundamental incompleto (11,8\%). (IBGE, 2015).

Quanto à mortalidade materna, as mulheres negras têm encabeçado os índices desfavoráveis deste tipo de óbito. As ocorrências de morte materna sinalizam a necessidade de atenção à saúde reprodutiva das mulheres. Ao relacionar as causas obstétricas diretas de óbito materno à dimensão cor/raça é possível verificar que as mulheres negras são atingidas em maior proporção por tais causas. 
Gráfico 03: Número de mortes maternas, segundo principais causas e cor ou raça (branca e negra) Brasil, 2000 e 2012.
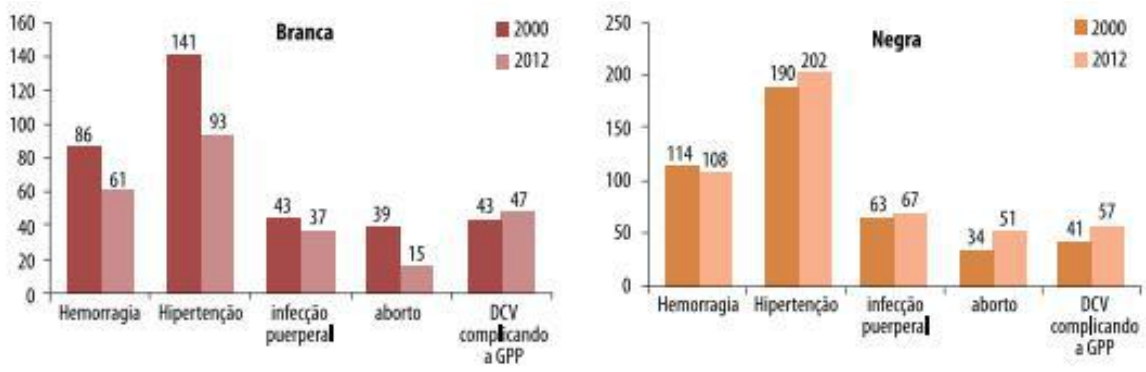

Fonte: Ministério da Saúde, 2016.

Quanto à violência obstétrica, tal prática tem atingido, conforme já mencionado, as mulheres negras de maneira mais intensa, já que a sociabilidade burguesa, no Brasil, se estruturou a partir das desigualdades de gênero, raça/cor e classe.

Entende-se por violência obstétrica a apropriação do corpo e dos processos reprodutivos das mulheres por profissional de saúde que se expresse por meio de relações desumanizadoras, de abuso de medicalização e de patologização dos processos naturais, resultando em perda de autonomia e capacidade de decidir livremente sobre seu corpo e sexualidade, impactando negativamente na qualidade de vida das mulheres (DINIZ, 2015, p. 03).

Os resultados encontrados na tese de doutorado da autora revelou uma relativa compreensão sobre o que é violência obstétrica por parte de profissionais de saúde e gestoras. Quanto à articulação entre e a dimensão racial, não foram identificadas ações que pudessem ser entendidas como formas mais consistentes de enfrentamento ao racismo, a despeito dos dados existentes no que diz respeito ao grupo que é mais atingido pela violência obstétrica no Brasil. Segundo Diniz (2015), a mortalidade materna pode ser entendida como uma das possíveis consequências da violência obstétrica. Neste contexto, as pesquisas apontam que as taxas de mortalidade materna são relacionadas ao acesso e à qualidade dos serviços de saúde ofertados, onde grande parte destas mortes poderiam ser evitadas através da aplicação adequada de políticas públicas a exemplo da PNSIPN. 
Neste sentido, uma das pretensões do estudo foi verificar o quanto a Política Nacional de Saúde Integral da População Negra (PNSIPN), datada de 2009, era utilizada como parâmetro para o atendimento às mulheres naquela unidade de saúde. A pergunta era: Será que a PNSIPN era conhecida pelas/os profissionais e gestoras? Em que medida essa política fez parte da formação profissional destes sujeitos? Será que a PNSIPN era considerada como elemento fundamental do Sistema Único de Saúde - SUS? Estas questões surgiram porque entendemos a necessidade da defesa intransigente do SUS no Brasil. Ao contrário do que muitos pensam, a PNSIPN reforça a necessidade da equidade em saúde, já que seus objetivos envolvem a garantia e ampliação do acesso da população negra, quer nas áreas urbanas, em particular nas regiões periféricas dos grandes centros, quer da população negra do campo e da floresta, em particular as populações quilombolas, às ações e aos serviços de saúde.

Atualmente, vivemos tempos de grave crise do sistema capitalista, aprofundada pela pandemia do Coronavírus (SARS-Cov-02) que provoca a doença chamada COVID-19, e a população negra tem sido ainda mais impactada em todas as dimensões da vida. No momento em que o país soma mais de 150 mil mortes, a Revista norte-americana Clinical Infections Diseases revelou que no Brasil "a mortalidade materna de mulheres pretas devido à Covid-19, o novo coronavírus, é quase duas vezes maior que a de mulheres brancas" (RIBEIRO, 2020, p. 01).

Diante destes fatos é possível afirmar que as necessidades sociais dos diferentes grupos não estão divorciadas da compreensão de como se estabelece as relações sociais a partir das dimensões de gênero, raça e classe. Assim, profissionais - especialmente Assistentes Sociais - precisam ser capazes de discutir tais temáticas.

\section{0 debate de gênero, raça e classe na formação de pro- fissionais na saúde}

A partir da preocupação com a abordagem que envolve mulheres negras e assistência obstétrica, a pesquisa da autora pretendeu verificar, a partir da formação de profissionais e gestoras de saúde entrevistadas/os, de que forma a PNSIPN esteve presente nestas oportunidades. A metodologia de análise foi baseada nos núcleos de sentidos atribuídos ao tema da pesquisa. Um desses núcleos identificou a ausência de temas relativos à saúde da população negra no processo formativo das/os envolvidas/os. Foi 
verificado que poucas gestoras e profissionais de saúde tiveram a oportunidade de aprofundar, durante a formação, análises a partir das categorias gênero, raça/cor e classe. Os relatos giraram em torno do desconhecimento em relação à PNSIPN ou pouco contato.

"A educação como prática da liberdade é um jeito de ensinar que qualquer um pode aprender" (HOOKS, 2013). É a partir desta concepção que a esperança emerge diante dos desafios postos para a construção de conhecimento e práticas, verdadeiramente, antirracistas. Conforme observado ao longo das entrevistas, a dinâmica sócio-histórica do Brasil, o legado escravista, a crença na democracia racial, a cristalização da imagem subalternizada da mulher negra, a impossibilidade de considerar a questão racial como determinante nas formas de acesso aos direitos e o silêncio diante das questões raciais são fatores que prejudicam o diálogo e a construção de uma realidade mais equânime para todas (os).

Neste processo, o caráter formativo se apresenta como fundamental, tanto para a liberdade quanto para a alienação no que tange aos efeitos do racismo. A proposta aqui é o investimento na educação como forma de liberdade, entendendo-a como uma estratégia necessária para que a cegueira diante da complexa questão racial brasileira se dissipe e/ou reforce o contingente de sujeitos comprometidos com a luta antirracista, quer sejam negros (as) ou brancos (as).

Estudos como os de Hotimsky (2009), Rocha (2014), Diniz et al (2015) e Cavalcanti et al (2012) são categóricos em afirmar a importância da educação, em todos os níveis, tendo em vista a garantia de direitos sociais. No que se refere a área da saúde, o Art. 200 da Constituição Federal de 1988, em seu inciso III, atribui ao SUS a competência de ordenar a formação dos recursos humanos na área da Saúde (BRASIL, 2016). Sendo assim, os fatores relativos à educação na saúde ganham destaque como atribuições do sistema.

Em relação à formação profissional das (os) entrevistadas (os), ao verificar suas trajetórias nos respectivos cursos superiores e pós-graduação, foi possível identificar que as temáticas raciais, praticamente, não foram abordadas. Apenas uma entrevistada revelou ter tido contato com a política na pós-graduação.

Já tive contato na época da especialização, mas, na maternidade em si eu ainda não vi uma ação específica nesse sentido (Profissional 01) (SANTOS, 2019, n/p). 
Já ouvi falar, mas, conhecer, conhecer a fundo não conheço não (Profissional 02) (SANTOS, 2019, n/p).

A PNSIPN tem como objetivo maior o combate ao racismo institucional na área da saúde. Sua promulgação resultou das lutas políticas travadas pelo movimento negro e movimento de mulheres negras com a intenção de que as instituições pudessem rever suas práticas cotidianas, possibilitando maior equidade à população negra a partir da atenção às suas especificidades epidemiológicas, sociais, culturais e econômicas.

Werneck (2014) informa que a especificidade da população negra no âmbito da saúde diz respeito às mortes precoces, doenças cardiovasculares e óbitos maternos. Essas incidências poderiam ser resolvidas com o que é disponibilizado, atualmente, no SUS. Para Werneck (2014), não há a necessidade de grandes investimentos tecnológicos para uma assistência que dê conta destes agravos, porém, não são vistos resultados neste sentido.

Os fundamentos do SUS são universalidade, integralidade e equidade. 0 referido sistema serve como modelo no que diz respeito a sua organi zação e pelo fato de se manter público, apesar das tentativas de privatização. Seus fundamentos ainda não foram alcançados efetivamente. Neste processo, a população negra tem sido, sistematicamente, prejudicada. Logo, a PNSIPN, a partir do reconhecimento do racismo, das desigualdades étnico-raciais e do racismo institucional como determinantes sociais das condições de saúde, busca preencher a lacuna das discrepâncias constatadas nos índices desfavoráveis de saúde da população negra.

A PNSIP é uma política focalizada, entretanto, a focalização deve ser entendida como uma forma de atentar para doenças geneticamente determinadas como: anemia falciforme e deficiência de glicose 6-fostato; as adquiridas em condições desfavoráveis como desnutrição, Infecções Sexualmente Transmissíveis (IST), HIV/AIDS, mortes violentas e nos tratamentos dificultados como a hipertensão arterial, diabetes, insuficiências renais e miomatoses. Deste modo, cabe ressaltar que o objetivo não é atender, exclusivamente, pessoas negras como muitos acreditam, mas de fazer com que a assistência seja integral. Esta perspectiva prima pela estratégia participativa, pauta-se em informações epidemiológicas para tomadas de decisões, isto é, evidências científicas e pelo fortalecimento do controle social.

No que diz respeito à assistência obstétrica, a PNSIPN chama atenção para as mortes maternas cuja ocorrência tem atingido perversamente as mulheres negras. Conforme dito, ao destacar as causas da morbimortali- 
dade, como hipertensão, coronariopatias e doença falciforme, por exemplo, a política visa contribuir para a diminuição de mortes maternas, já que qualifica gestoras (es) e profissionais de saúde para o atendimento às mulheres que apresentam incidências destas doenças, pois a identificação destes casos possibilita a redução de agravos e óbitos no período gravídico puerperal.

A partir da concepção ancestral africana de oralidade (transmissão e troca de saberes); corporeidade; energia vital, memória; religiosidade; musicalidade; comunitarismo; território e circularidade (UNASUS, 2019), a PNSIPN oferece a oportunidade dos agentes do SUS pensarem e intervirem na perspectiva de redução de desigualdades. As alternativas trazidas pela referida política refere-se a um atendimento pautado na centralidade do outro enquanto ser humano onde a filosofia africana fornece elementos capazes de superar o individualismo nas relações profissionais de saúde/ usuárias (os).

O pouco conhecimento da PNSIPN e sua implantação na rotina da maternidade pesquisada é reflexo das complexidades que envolvem a questão racial no Brasil, que impede considerar a existência de mortes negras como àquelas que não tem causas em doenças, mas em causas evitáveis como os óbitos violentos, a mortalidade materna, enfim, causas mal definidas (BATISTA, ESCUDER, PEREIRA, 2004). Neste sentido, o não investimento nesta política, no que se refere à articulação entre a mesma e o processo formativo de profissionais e gestores/as da saúde, acarreta prejuízos para todas (os).

Forjar oportunidades para a reflexão e ação sobre a determinação social de gênero e raça na saúde, a partir da formação, torna-se fundamental, já que o cotidiano laboral, que exige a execução de multitarefas, não possibilita às (aos) profissionais criticidade diante das ações e práticas que produzem. A discriminação racial é alimentada pelo não questionamento aos estereótipos impostos, secularmente, às pessoas negras. Logo, a discussão sobre violência obstétrica com viés racial está longe de provocar separações. Ao fomentar ações para a extinção do racismo institucional, a PNSIPN objetiva garantir, dentre outras questões, que a gestante negra possa ser entendida em suas especificidades. Dessa forma, ao privilegiar o cuidado, a política preconiza o alcance da melhor assistência para todas as mulheres. 


\section{Considerações finais}

A realidade da sociedade brasileira é marcada por uma dinâmica pautada nos ditames de um capitalismo dependente, cujas bases se firmam no racismo estrutural e nas desigualdades de gênero e de classe. Neste contexto, a população negra, formada por pessoas pretas e pardas, com destaque para as mulheres negras, vivenciam os efeitos deletérios desta dinâmica onde os índices de desemprego, baixo acesso à saúde, complexas condições educacionais e de moradia determinam o quadro de desigualdade extrema da qual este grupo social é, majoritariamente, representado.

Diante disso, cabe a indagação de como profissionais de saúde tem se comportado ao se deparar com as necessidades da população atendida pelo SUS, com destaque para mulheres negras grávidas e puérperas. As necessidades biológicas, articuladas às necessidades sócio-econômicas e raciais cotidianas se apresentam na relação institucional. Logo, cabe perguntarmos de que forma essas mediações são feitas na assistência obstétrica para as mulheres negras e suas famílias?

0 objetivo deste texto foi de demonstrar a urgente necessidade de investimento no debate étnico-racial na formação de profissionais de saúde, com destaque para a formação em Serviço Social. Tal urgência se revela como algo a ser considerado com profundidade pelas instituições formativas a partir da complexa e particular realidade sócio histórica brasileira. Logo, é necessário e urgente efetivar propostas pedagógicas que acionem os sentidos para a apreensão das relações raciais de forma totalitária e robusta, tendo em vista o caráter interventivo do Serviço Social nas demandas sociais que, em grande medida, são apresentadas pela população negra.

A partir da discussão sobre a formação em Serviço Social e as possibilidades de debater gênero, raça e classe com base nas suas diretrizes curriculares, é aberto o espaço para chamar atenção da necessidade de investimento não só nesta profissão mas, fundamentalmente, em todas as profissões da área da saúde, desde a mais elementar até a mais complexa. Superar os obstáculos impostos ao enfrentamento ao racismo institucional requer estratégias que garantam integração das pessoas negras nos serviços de saúde. No que diz respeito à assistência ao período gravídico puerperal sugere-se ações educativas articuladas entre a Política Nacional de Educação Permanente em Saúde, a PNSIPN e, ainda, a educação popular em saúde, tendo em vista a necessidade de qualificação profissional capaz de dialogar de fato com a população usuária dos serviços de saúde, em especial, as maternidades. Tal ação materializa a integralidade e a intersetorialidade, 
princípios fundamentais do SUS. Neste sentido, é preciso investimento numa cultura institucional que favoreça a prática profissional baseada em evidências de modo que, cotidianamente, profissionais de saúde e gestoras (es) repensem suas ações para melhorar o cuidado de saúde, tornando eficaz a experiência da pessoa usuária do SUS. É recomendável ainda que gestoras (es) da política de saúde tenham em vista os fundamentos do controle social, ou seja, da participação da sociedade para intervir no SUS. A participação do movimento de mulheres negras e do movimento negro não pode deixar de ser considerada nesta dinâmica.

\section{Referências}

ALMEIDA, S. de. 0 que é racismo estrutural? Minas Gerais: Letramento, 2018.

ABEPSS/CEDEPSS. Diretrizes Gerais para o Curso de Serviço Social (com base no currículo mínimo aprovado em Assembleia Geral Extraordinária de 8 de novembro de 1996) In: Cadernos ABESS - Formação Profissional: Trajetórias e Desafios, n.7, Cortez: São Paulo 1997, p. 58-76.

ABESS/CEDEPSS. Proposta básica para o projeto de formação profissional. In: Revista Serviço Social e Sociedade. São Paulo: Cortez, ano XVII, n. 50, 1996.

BARROCO, M. L. S. Barbárie e neoconservadorismo: os desafios do projeto ético-político. In: Serviço Social e Sociedade, São Paulo, n. 106, p. 205218, jun. 2011. Disponível em: <http://www.scielo.br/scielo.php? script=sci_arttext\&pid=S0101-66282011000200002\&lng=pt\&nrm=iso > . Acesso em: 05 dez. 2019.

BATISTA, L. E.; ESCUDER, M. M. L.; PEREIRA, J. C. R. A cor da morte: causas de óbito segundo características de raça no Estado de São Paulo, 1999 a 2001. Revista de Saúde Pública, São Paulo, v. 38, n. 5, p. 630-636, 2004. Disponível em: <http://www.scielo.br/scielo.php? script=sci_arttext\&pid=S0034-89102004000500003\&lng=en\&nrm=iso >. Acesso em: 28 ago. 2017.

BRASIL. Ministério da Saúde. Secretaria de Gestão Estratégica e Participativa. Departamento de Articulação Interfederativa. Temático Saúde da População Negra. Brasília: Ministério da Saúde, 2016, 86 p. Disponível em: 
<http://portalarquivos.saude.gov.br/images/pdf/2016/maio/13/painel10-130516.pdf>. Acesso em: 10 dez. 2016.

BRASIL. Ministério da Educação. Conselho Nacional de Educação. Diretrizes Curriculares Nacionais para a Educação das Relações Étnico-Raciais e para o Ensino de História e Cultura Afro-Brasileira e Africana. Parecer CNE/CP 003/2004. Brasília: CNE, 2004. Disponível em: <http:// portal.mec.gov.br/dmdocuments/cnecp_003.pdf>. Acesso em: 27 ago. 2019.

\section{Constituição da República Federativa do Brasil (1988): texto} constitucional promulgado em 5 de outubro de 1988, com as alterações determinadas pelas Emendas Constitucionais de Revisão nos 1 a 6/94, pelas Emendas Constitucionais nos 1/92 a 91/2016 e pelo Decreto Legislativo no 186/2008. - Brasília: Senado Federal, Coordenação de Edições Técnicas, 2016. Disponível em: <https://www2.senado.leg.br/bdsf/bitstream/handle/id/518231/CF88_Livro_EC91_2016.pdf>. Acesso em: 24 ago. 2019.

CAVALCANTI, L. F.; FLACH, R. M. D.; FARIAS, R. S. Atenção às mulheres em situação de violência sexual nos serviços de saúde do Estado do Rio de Janeiro. In: 0 Social em Questão, Ano XV, n. 28. Rio de Janeiro: Departamento do Serviço Social da PUCI-Rio, p. 99-124, 2012. Disponível em: <http://osocialemquestao.ser.puc-rio.br/media/6artigo.pdf>. Acesso em: 24 ago. 2019.

DINIZ, C. S. G. (et al). Violência obstétrica como questão para a saúde pública no Brasil: origens, definições, tipologia, impactos sobre a saúde materna, e propostas para sua prevenção. In: Revista brasileira de crescimento e desenvolvimento humano, v. 25, n. 3, p. 377-384, 2015. Disponível em: <http://pepsic.bvsalud.org/scielo.php?pid=S010412822015000300019\&script=sci_arttext>. Acesso em: 20 ago. 2015.

D'ORSI, E. (et al). Desigualdades sociais e satisfação das mulheres com o atendimento ao parto no Brasil: estudo nacional de base hospitalar. In: Cadernos de Saúde Pública. Rio de Janeiro, v. 30, supl. 1, p. S154-S168, 2014. Disponível em: <http://www.scielo.br/scielo.php?script=sci_arttext\&pid=S0102-311X2014001300021\&lng=en\&nrm=iso $>$. Acesso em: 12 jan. 2017.

HOOKS, B. Ensinando a transgredir: a educação como prática da liberdade. Trad. Marcelo Brandão Cipolla. São Paulo: Ed. WMF Martins Fontes, 2013. 
HOTIMSKY, S. N. A violência institucional no parto no processo de formação médica em obstetrícia. In: Anais do I Encontro Nacional de Antropologia do Direito. Universidade de São Paulo. p. 1-13, 2009. Disponível em: <https://www.researchgate.net/publication/268425794_A_violencia_institucional_no_parto_no_processo_de_formacao_medica_em_obstetricia>. Acesso em: 23 fev. 2017.

IBGE. Pesquisa Nacional de Saúde 2013: ciclos de vida: Brasil e grandes regiões / IBGE, Coordenação de Trabalho e Rendimento. Rio de Janeiro: IBGE, 2015. Disponível em: <https://biblioteca.ibge.gov.br/visualizacao/livros/ liv94522.pdf>. Acesso em: 08 set. 2019.

Desigualdades Sociais por Cor ou Raça no Brasil. In: Estudos e Pesquisas Informação Demográfica e Socioeconômica, n. 4. Rio de Janeiro: IBGE, 2019. Disponível em: <https://www.ibge.gov.br/estatisticas/ sociais/populacao/25844-desigualdades-sociais-por-cor-ou-raca.html? edicao $=25845 \& \mathrm{t}=$ sobre $>$. Acesso em: 20 nov. 2019 .

\section{LIMA, S. C. de S. 0 corpo escravo como objeto das práticas médicas no} Rio de Janeiro (1830-1850). 2011. 208 f. Tese (Doutorado em História das Ciências e da Saúde) - Casa de Oswaldo Cruz. Rio de Janeiro: Fiocruz, 2011. Disponível em: <https://www.arca.fiocruz.br/bitstream/icict/ 16349/2/129.pdf>. Acesso em: 20 ago. 2019.

MOTT, M. L. B. 0 curso de partos: Deve ou não haver parteiras? In: Cadernos de pesquisa, n. 108, p. 133-160, 1999. Disponível em: <http://www.scielo.br/scielo.php?script=sci_arttext\&pid=S010015741999000300006\&lng=pt\&nrm=iso>. Acesso em: 26 ago. 2019.

PERPÉTUO, I. H. O. Raça e acesso às ações prioritárias na agenda da saúde reprodutiva. In: XII ENCONTRO NACIONAL DE ESTUDOS POPULACIONAIS. CAXAMBU, MG. Anais eletrônicos... Caxambu, Associação Brasileira de Estudos Populacionais - ABEP: 2000, p. 1-14. Disponível em: <http://www.abep.org.br/publicacoes/index.php/anais/article/view/1051/1016>. Acesso em: 11 jul. 2018.

RIBEIRO, F. Pretas grávidas e no pós-parto morrem mais por Covid-19 do que brancas. Alma Preta. [S.l.]. 06 ago. 2020. Cotidiano. Disponível em: $<$ https://almapreta.com/sessao/cotidiano/pretas-gravidas-e-no-posparto-morrem-mais-por-covid-19-do-que-brancas> . Acesso em 18 nov. 2020. 
ROCHA, R. da F.. A questão étnico-racial no processo de formação em Serviço Social. Serviço Social e Sociedade, São Paulo. n. 99, p. 540-561, 2009.

A inserção da temática étnico-racial no processo de formação em Serviço Social e a sua relação com a educação antirracista. In: ABRAMIDES, Maria Beatriz; DURIGUETTO, Maria Lúcia (Orgs.). Movimentos Sociais e Serviço Social: uma relação necessária. São Paulo: Cortez, 2014.

A construção do pensamento racial brasileiro. Aula proferida na disciplina Gênero, Violência e Políticas Públicas do Programa de Pós-Graduação em Serviço Social (Doutorado) da Universidade Federal do Rio de Janeiro - UFRJ, 2015. Rio de Janeiro, 2015.

SANTOS, J. F. de A. dos. Enfrentamento à violência obstétrica contra mulheres negras numa maternidade pública municipal do Rio de Janeiro a partir das perspectivas de gestoras (es) e profissionais de saúde. 2019. 190f. Tese (Doutorado em Serviço Social). Programa de Pós-Graduação em Serviço Social, Universidade Federal do Rio de Janeiro, Rio de Janeiro, 2019. Disponível em: <https://sucupira.capes.gov.br/sucupira/public/ consultas/coleta/trabalhoConclusao/viewTrabalhoConclusao.xhtml?popup=true\&id_trabalho=7732167>. Acesso em 20 out. 2020.

UNASUS. Universidade Aberta do SUS. Curso on line: Módulo Saúde Integral da População Negra. Uni. 01. Ministério da Saúde: UNASUS, 2019.

WERNECK, J. Racismo institucional e saúde da população negra. Saúde e Sociedade, São Paulo. v. 25, n. 3, p. 535-549, 2016 . Disponível em: <http://www.scielo.br/scielo.php?script=sci_arttext\&pid=S0104$12902016000300535 \& \operatorname{lng}=e n \& n r m=i s o>$. Acesso em: 28 ago. 2019.

WERNECK, J. 'Internalização do racismo afeta a saúde'. Radis: Saúde da População Negra. 2014, v. 142, n. 20, p.14-15. Jul. 2014.

WISNIEWSKI, A. P. (In) Visibilidade negra. Núcleo de Direitos Humanos da Universidade Vale dos Sinos. Rio Grande do Sul, 2013. Disponível em: <http://unisinos.br/blogs/ndh/2013/09/30/invisibilidade-negra/>. Acesso em: 30 jul. 2019. 